https://doi.org/10.48009/2_iis_2007_225-231

\title{
CAN HEATHER GILLETTE SAVE YOUTUBE? INTERNET SERVICE PROVIDERS AND COPYRIGHT LIABILITY
}

\author{
David Griffith, Austin College, dgriffith@austincollege.edu \\ Bryan McKinney, Ouachita Baptist University, mckinneyb@obu.edu
}

\begin{abstract}
The phenomenal growth of Internet service provider YouTube has already raised the company to legendary status. When Google acquired the company in 2006, YouTube's founders became billionaires. But YouTube's future success is contingent upon its ability to avoid copyright liability lawsuits that destroyed an earlier generation of online firms like Napster and Grokster. This paper describes YouTube's products and technology, summarizes the potential legal case against YouTube, discusses the relevant legal precedents, and concludes with an assessment of YouTube's future legal challenges.
\end{abstract}

Keywords: Information Technology (IT), Internet Service Provider, Law, Copyright, Digital Millennium Copyright Act (DMCA)

\section{INTRODUCTION}

The tension between technological innovation and copyright protection has often baffled policy makers, particularly in the Internet age. Most agree that innovation should not be stifled; however, most also agree that intellectual property should be respected. When these two vitally important concepts collide, the result can generally be described with one word: litigation.

From Sony's Betamax to YouTube, technological innovations often invite litigation over alleged copyright violations. Legislators and courts have struggled to strike a workable balance between the rights of intellectual property owners and the rights of innovators. Law and policy has failed to keep up with technology. Two recent decisions involving music copyright, A\&M v. Napster and MGM v. Grokster, found the Internet technology firms liable for copyright infringement by users of the services [1, 12]. These decisions portend more difficulty ahead for Internet service providers.

This paper focuses on what may be the next battleground between technological innovators and copyright holders - online video. YouTube and similar web sites such as Video.AOL.com and Joost promise users virtually unlimited access to video content. While the specific methodologies and license agreements vary between providers of online video, all of the services allow users to upload, search for, and view video content, some of which may be protected by copyright restrictions.

When users upload and view copyrighted digital video content, are these online video services subject to liability for copyright infringement? The answer hinges on the strength of the safe harbor provision imbedded within the Digital Millennium Copyright Act (DMCA) [4]. A critical component of the DMCA's safe harbor provision is the designation of an agent who is responsible for responding to complaints from aggrieved copyright holders.

The purpose of this paper is to preview the emerging legal issues facing Internet delivery of online videos by focusing on the industry leader, YouTube. Broadly speaking, is a reactive stance to copyright liability sufficient to save YouTube and similar firms? More specifically, YouTube's designated DMCA agent is Heather Gillette. Can Heather Gillette's actions as DMCA agent save YouTube from copyright liability?

\section{YouTube's Rise to Prominence}

YouTube (www.YouTube.com) is an Internet service that allows user to upload, search for, and view video content. Users can upload digital video content of their own creation, such as a short film, documentary, or scene captured on a digital recorder, or content that has been copied from another supplier, such as content recorded from a digital video disc (DVD). The search mechanism allows users to look for videos categorized by keywords. Users can then view the videos in the form of streaming media, which allows them access to the video content with little to no delay, depending primarily on the speed of the user's Internet connection. 
Wooley [18] reports that YouTube's first videos, on May 5, 2005, included pictures of YouTube's founders, Steve S. Chen and Chad Hurley hanging out in Hurley's garage. YouTube's immediate appeal was its unique combination of community and voyeurism, promoted by YouTube's slogan, "Broadcast Yourself." Unlike the online music services which preceded it, YouTube encouraged its users to create original content, rather than simply rebroadcast other's intellectual property. YouTube may have anticipated an emerging social trend, but by encouraging the creation of original works, it may have also helped to create a safe legal space for itself.

The Internet rating agency Alexa (www.alexa.com) reports that YouTube's rise has been meteoric, moving from non-existent to the fourth most visited web site in the world in only 18 months, reaching almost $9 \%$ of all Internet users daily.

YouTube is a global phenomenon. According to Alexa, YouTube is the $3^{\text {rd }}$ most visited site in the Philippines, the $4^{\text {th }}$ most visited site in Venezuela, the $5^{\text {th }}$ most visited site in Mexico, and the $6^{\text {th }}$ most visited site in Japan. While the United States continues to struggle with the appropriate balance between innovation and copyright protection, the international community is also grappling with these issues. International copyright protection is beyond the scope of this brief paper, but it is certainly a topic worth noting. Dodes [7] articulates several of the interesting challenges facing the international community and concludes that the public must be patient as the major issues are sorted out.

YouTube's start-up success quickly attracted the attention of other Internet firms and made it an acquisition target. On October 6, 2006, Google announced that it had reached an agreement to acquire YouTube for $\$ 1.65$ billion in a stock-forstock transaction, and the deal was closed on November 3, 2006. According to Google's statements, Google will allow YouTube to operate independently, with Google contributing technology and advertising relationships [8, 9]

Some analysts are beginning to question the wisdom of the Google purchase. Berzon [5] reported that recently released earnings statements reveal that YouTube earned about $\$ 15$ million in sales in 2006, less than $1 \%$ of its purchase price. Berzon reports that an even more significant problem for Google's YouTube unit is the looming possibility of copyright litigation, with Viacom, CBS, and NBC all unhappy with YouTube both for allegedly failing to prevent copyright violations and share copyright revenues [5]. Viacom's dissatisfaction with YouTube's handling of Viacom properties recently resulted in a $\$ 1$ billion lawsuit against YouTube and parent Google [2].

\section{Tur v. YouTube - a test case}

Despite the many complaints and threats of litigation, as of the date of this writing, YouTube has been sued rarely for copyright violation. While more prominent plaintiffs have filed suit against YouTube (Viacom [2] American Airlines [3] and Paramount Pictures [13], for example) Robert Tur has filed a case that may serve as a road map for others seeking to hold providers of online video accountable for users' copyright violations [14]. The Tur v. YouTube case once again asks the Court whether or not technological innovation may trump copyright protection.

On July 14, 2006, prior to YouTube's acquisition by Google, Robert Tur, doing business as Los Angeles News Service, filed suit in the United States District Court of California. Mr. Tur, an Emmy winning freelance photographer, alleges that his copyrighted videos are being distributed, copied, and publicly displayed throughout the world through YouTube's website. For example, Mr. Tur shot video of the beating of trucker Reginald Denny during the 1992 riot in Los Angeles. As measured by YouTube.com's own view feature counter, various versions of this clip have been viewed in excess of 5,500 times. Mr. Tur claims that each viewing is an infringement of his copyright. Tur seeks an injunction that would bar this and other of his videos from the site, and for substantial monetary damages based on the claim that these viewings represent unauthorized use and a reduction in the future value of Tur's intellectual property.

YouTube answered Tur's complaint [14] by invoking the "safe harbor" provision of the Digital Millennium Copyright Act (DMCA). The DMCA allows Internet Service Providers (ISPs) immunity from copyright liability under limited circumstances [4]. The concept behind the safe harbor provision is that ISPs should be treated more as transporters of information than as 
publishers of information. Since ISPs do not create content, under most circumstances they are not responsible for the content posted by their users.

However, in the days leading to Google's acquisition of YouTube, Thaw [17] reported that Google established a \$200 million reserve fund to protect against potential copyright lawsuits. The fund indicates that YouTube's reliance on the DMCA's safe harbor provision may be headed toward rough seas.

\section{The Digital Millennium Copyright Act's Safe Harbor}

Under certain scenarios, the DMCA limits liability "for infringement of copyright by reason of the storage at the direction of a user of material that resides on a system or network controlled or operated by or for the service provider."[4] In order to enjoy the safe harbor protections, service providers must designate an agent to receive notification of claimed infringement.

Service providers will lose the safe harbor protections if they: 1) have actual or constructive knowledge that the material or an activity using the material on the system is infringing; 2) receive a financial benefit directly attributable to the infringing activity (in a case where the service provider has the right and ability to control such activity); or, 3) fail to expeditiously remove or disable access to the infringing material or activity [4].

By all accounts, YouTube promptly removes or disables infringing material upon receiving notification of such activity. However, applying YouTube's business model to the first two of these three elements leads one to think that YouTube's safe harbor may not be so safe.

Does YouTube have actual or constructive knowledge that infringing material exists on its system? YouTube claims that it receives this knowledge only when notified by the copyright holder. But if a first time YouTube user cannot avoid finding infringing material, surely its existence hasn't gone unnoticed by YouTube itself. YouTube has significant exposure because the material exists on its own centrally managed and controlled system.
Does YouTube receive a financial benefit directly attributable to the infringing activity? If so, does YouTube have the right and ability to control the infringing activity? Unfortunately for YouTube, the good citizenship it practices regarding other content might subject the company to greater scrutiny on this point. For example, video postings containing pornographic and violent content are filtered. YouTube may argue that filtering pornographic content is an easier task than filtering copyrighted content, but given the company's technological sophistication, this argument may not generate much sympathy.

In the U.S. legal system, judges determine issues of law, and juries determine issues of fact. At a minimum, the question of whether or not YouTube can control the infringing activity is a question of fact. This means that Tur and similar future plaintiffs will be able to present their arguments to juries, which is no small concern to a service provider's legal counsel.

Is a financial benefit directly attributable to the infringing activity? It appears so. YouTube's business model is similar to that once utilized by Grokster, wherein the companies earn money through advertising - as usage increases, so does advertisement revenue. When the Supreme Court had the occasion to comment on Grokster's business model in 2005, it noted: "Since the extent of the software's use determines the gain to the distributors, the commercial sense of their enterprise turns on high-volume use, which the record shows in infringing." [12]. The same may be said of YouTube.

In the event that the DMCA safe harbor is inapplicable, then YouTube will be scrutinized under the Sony, Napster, and Grokster trilogy $[16,1,12]$.

\section{The Technology Trilogy: Sony, Napster \& Grokster}

Well before the Internet era, the Sony case (Sony Corp. v. Universal City Studios, Inc., 1984), established legal precedent governing technology which might be capable of violating copyright. Borrowing from patent law, the US Supreme court applied the staple item of commerce doctrine. This doctrine holds that an item which has significant legitimate uses cannot be prohibited because of potential illegitimate uses. Sony was producing and marketing the Betamax 
video recording system, which Sony acknowledged had both legitimate and illegitimate uses. With the same device, one could lawfully record a television program for later viewing, or, one could unlawfully make multiple copies of a television program to distribute for resale [16]. The Sony decision was a clear victory for technology innovators, as it stands for the proposition that the legitimate use of the technology trumps its potential misuse.

The Napster and Grokster decisions, discussed below, cast doubt on whether courts will rely on Sony in the Internet era. But, if a court were to do so, it would most likely work to the benefit of YouTube. The substantial non-infringing uses of YouTube, such as sharing homemade videos, would legitimate the technology, even though the technology makes possible substantial infringement.

Some have suggested a modification of the rule articulated in Sony. For example, Helton [10] suggests that the definition of staple articles of commerce should include all products with substantial noninfringing uses, except those that: 1) are capable of large-scale copyright infringement through wide-spread distribution of copyrighted works; and, 2) do not incorporate reasonable filtering or preventative methods to curb unauthorized reproduction and distribution of copyrighted works. With this modification, perhaps Sony could be of greater value in cases involving current technology and copyright issues. As it is currently operated, YouTube likely would fall outside of this modified definition of a staple article of commerce; however, if the company determined to implement reasonable filtering or other preventative methods, it could be shielded from copyright liability.

Faced with growing technological challenges, rather than modifying the blanket protection offered in Sony, courts have worked hard to distinguish cases from the Sony precedent. In A\&M Records v. Napster, (2001), the $9^{\text {th }}$ Circuit held that Napster was not merely an innocent bystander whose technology was being misused, but an active facilitator in copyright abuse. The court held that Napster, a centralized file-sharing network controlled on a single computer node, was legally liable for the copyright infringement that took place on its network. Rights of reproduction and distribution - two of the exclusive rights of copyright holders - were deemed to have been infringed. Further, the court concluded, "Napster, by its conduct, knowingly encourages and assists the infringement of plaintiffs' copyrights...(W)e place the burden on plaintiffs to provide notice to Napster of copyrighted works and files containing such works available on the Napster system before Napster has the duty to disable access to the offending content. Napster, however, also bears the burden of policing the system within the limits of the system." [1].

Applying the Napster precedent to YouTube, courts would need to answer two major questions: 1) Does YouTube encourage and assist its users to infringe on copyrights; and, 2) Does YouTube police its system within the limits of the system? While YouTube does not encourage copyright abuse, its very existence assists users who upload and download copyrighted videos. Like Napster, YouTube is a centralized system which is controlled internally. Though YouTube may be diligent in removing copyrighted content once it is notified of alleged infringement, it could be far more diligent in policing its content. YouTube's rival in social networking, MySpace, has been much more aggressive in placing filters which automatically monitor and restrict files with tags identifying them as copyright. A court may well decide that YouTube's failure to install similar filters indicates a willingness to facilitate copyright abuse by its customers.

The third and most recent legal precedent also originated in the $9^{\text {th }}$ Circuit, and was eventually decided by the United States Supreme Court. Grokster [12] was a business specifically designed to avoid the legal entanglements that brought down Napster. Their system was purposely designed so that there was no centralized node that could be controlled by management, relying instead on distributed nodes controlled by individual users. Grokster argued that since it was impossible for them to know precisely what copyrighted works were being infringed by users, they were exempt from the liability that Napster incurred.

Grokster's defense relied heavily on the Sony precedent, claiming that its product was capable of substantial non-infringing uses. Many Supreme Court watchers eagerly awaited the Court's decision, in hopes that it would offer some clarification on the delicate balance between copyright protection and technological 
innovation. The Court refused to acquiesce, and decided "to leave further consideration of the Sony rule for a day when that may be required." [12].

Even if Grokster had no direct control of content, the Supreme Court determined that Grokster implicitly encouraged and profited from copyright abuse. Just as it had done in the Sony case, the Court once again borrowed from patent law, and held found that Grokster could be liable for inducing copyright abuse. The Court stated, "For the same reasons that Sony took the staplearticle doctrine of patent law as a model for its copyright safe-harbor rule, the inducement rule, too, is a sensible one for copyright. We adopt it here, holding that one who distributes a device with the object of promoting its use to infringe copyright, as shown by clear expression or other affirmative steps taken to foster infringement, is liable for the resulting acts of infringement by third parties." [12].

The future impact of the Grokster decision is sharply debated. For example, Bryan Choi begins his article, The Grokster Dead-End, with the sentence, “Grokster is so 2005.”[6]. The clear implication is that the Grokster decision has no future value. Levin, on the other hand, concludes her article by claiming, "MGM v. Grokster will be a landmark case in the realm of peer-to-peer file sharing.” [11].

While the Grokster decision may be limited to cases of clear inducement, technology innovators would be well advised to distinguish their activities from those of Grokster. The Court pointed to three actions that showed the company acted with the purpose of causing copyright violations by its software users. First, Grokster marketed itself to former Napster users, which were a known source of demand for copyright infringement. Second, the company did not attempt to implement or design filtering tools that would limit the unlawful infringing activity. Finally, the Court focused on the fact that Grokster earned money through advertising, which turns on high-volume use, much of which was infringing [12].

Applying the Grokster precedent to YouTube, a plaintiff would need to establish that YouTube induced its users to violate copyright. Compared to Grokster, which made its software perfectly compatible with Napster and even bought mailing lists from Napster, YouTube exhibits much less malevolence. YouTube's diligence in removing content when it receives a complaint, and the way in which it distributes content in streaming form, making it difficult for users to save permanent copies, would reduce potential liability. However, it is not difficult to imagine a scenario in which YouTube might be determined to have fallen into some of the same legal errors as Grokster. Has YouTube implemented filtering tools? Is their source of revenue inappropriately linked to high volume usage of an infringing nature? If YouTube borrows the targeted adverting lessons from its parent Google, and links advertising content to copyright infringing material, it will profit from users' infringements. Such activity spelled doom for Grokster, and it may do the same for YouTube. The more profit YouTube makes from advertising even inadvertently linked to copyrighted content, the greater its potential for copyright liability.

\section{CONCLUSION}

In this paper, we have briefly summarized the potential copyright liability case against YouTube. We have established that while copyright infringement is a byproduct but not the purpose of YouTube's business, YouTube may face potentially damaging or even destructive copyright liability. The case of Tur v. YouTube is potentially a watershed case. While most cases settle out of court, if Mr. Tur insists on his day in court, his case could represent YouTube's perfect storm.

First, Mr. Tur must convince a jury that YouTube has knowledge of infringing activity, and that YouTube reaps a financial benefit that is directly related to infringing activity that it could have been controlled. If successful on this point, YouTube will be without the protection of the DMCA's safe harbor.

Absent this safe harbor, YouTube must then withstand scrutiny under Sony, Napster, and Grokster. As for Sony's applicability, it is unlikely that courts would apply an unmodified staple article of commerce doctrine. The Supreme Court may have tipped its hand in the Grokster decision by focusing on the company's failure to implement filtering tools that would have limited infringing activity. It appears that Sony will either be modified, or ignored, in future technology cases. In any event, it is unlikely that YouTube will find success in 
arguing that its services are capable of significant noninfringing uses.

A\&M Records v. Napster seems to offer a close analogy and a strong legal precedent for YouTube. Like Napster, YouTube is a centralized network with significant management oversight. Like Napster, YouTube has resisted installing software filters which would automatically reduce copyright abuse.

In contrast to Napster, YouTube has attempted to limit its liability, however. Its streaming technology prevents users from easily making permanent copies, and the company has been compliant with DMCA requests to remove infringing material.

Finally, the Grokster decision presents significant legal challenges to YouTube's current business model. Because of YouTube's reliance on advertising revenue which may be linked to infringing activity, and because of YouTube's refusal to implement effective filtering tools, it may be susceptible to liability based on Grokster's inducement theory of copyright liability.

YouTube now stands at a crossroad. The company can continue to be somewhat lax in its efforts to prohibit copyrighted material, or it can increase its efforts to intercept copyrighted messages through strict content filters. It can negotiate sharing contracts with copyright holders, or it can ignore copyright holders' needs and lose revenue sharing contacts while elevating potential liability risks.

What is the future of YouTube? Will it be the next killer app? Or will it allow copyright liability to destroy the business, like Napster and Grokster? Until recently, the work of Heather Gillette, YouTube's designated DMCA notification agent, has managed to keep litigation against YouTube to a trickle. Judging by the recent Viacom lawsuit, it appears YouTube is headed toward more litigation. Gillette's quick response may not ultimately save YouTube. Rather, YouTube must transition from a reactionary mode to a preventative one if it is to successfully avoid future lawsuits. Increased utilization of copyright filters may offer the only hope of preventing the trickle from becoming a torrent.

\section{REFERENCES}

1. A\&M Records, Inc. v. Napster, Inc., 239 F.3d 1004 (9th Cir. 2001)

2. Auchard,Eric and Duncan Martell, "Viacom Lawsuit Challenges Internet Business Model,” Reuters, March 13, 2007, retrieved online from http://www.reuters.com/article/reutersEdge/i dUSN1316259920070313?src=031307_164 6.

3. American Airlines v. You tube, Inc., U.S.District Court, Northern District, California, Docket \# 5:06MC80035; filing date $2 / 24 / 06$.

4. Digital Millennium Copyright Act, 17 U.S.C. §512(c)(1) (1998).

5. Berzon, Alexandra (2007), "Is YouTube a Google-Sized Distraction?” Red Herring, March 8, 2007, retrieved online from http://www.redherring.com/ Article.aspx?a=21567\&hed=Is + You Tube $+\mathrm{a}+$ GoogleSized+Distraction\%3F .

6. Choi, Bryan, "The Grokster Dead-End,” 19 Harvard Journal of Law and Technology 393 (2006)

7. Dodes, Jeffrey L., "Beyond Napster, Beyond the United States: The Technological and International Legal Barriers to online Copyright Enforcement," 46 N.Y.L. Sch. L. Rev. 279 (2003).

8. Google Press Release (2006), "Google Closes Acquisition of YouTube,” November 13, 2006, retrieved online at http://www.google.com/press/pressre l/google_youtube.html.

9. Google Press Release (2006), "Google to Acquire YouTube for $\$ 1.65$ Billion in Stock" October 9, 2006, retrieved online at http://www.google.com/press/pressre l/google_youtube.html.

10. Helton, Matthew, "Secondary Liability for Copyright Infringement: Bittorrent as a Vehicle for Establishing a New Copyright Definition for Staple Articles of Commerce”, 40 Columbia Journal of Law and Social Problems 1 (2006).

11. Levin, Dana, "The Future of Copyright Infringement: Metro-Goldwyn-Mayer Studios, Inc. v. Grokster, Ltd”, 21 Saint John's Journal of Legal Commentary, 271 (2006 
12. MGM Studios, Inc. v. Grokster, Ltd. 545 U.S. 913 (2005)

13. Paramount Pictures Corporation v. YouTube, Inc., U.S. District Court, Northern District of California, Docket \#3:06MC80098; filing date 5/04/06.

14. Robert Tur v. YouTube Inc., U.S. District Court, Central District of California, Docket \#2:06CV04436; filing date 7/14/06.

15. Sandoval, Greg, "YouTube sued over Copyright Infringement, "July 18, 2006, CNET News.com, retrieved online at http://news.zdnet.com/21009588_22-6095736.html.

16. Sony Corp. v. Universal City Studios, Inc., 464 U.S. 417, 449-50 (1984).

17. Thaw, Jonathan, “Google's \$200 Million Legal Reserve Underscores YouTube Worries” Bloomberg, November 15, 2006, retrieved online at

http://www.bloomberg.com/apps/ne ws?pid=20601087\&sid=at8yc9NCGj 0w\&refer=home.

18. Wolley, Scott, "Raw and Random," Forbes, March 13, 2006, retrieved online from http://members.forbes.com/global/20 06/0313/027.html. 